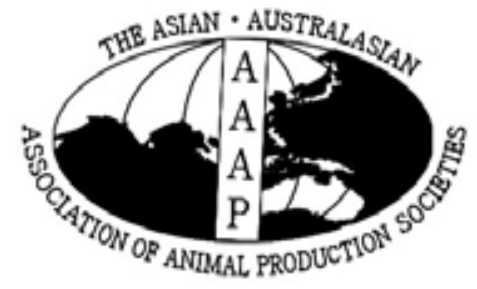

Asian-Aust. J. Anim. Sci.

Vol. 20, No. 1 : 31 - 35

January 2007

www.ajas.info

\title{
Effects of Ovarian Morphology and Culture Vessel on In vitro Development and Cell Number in Embryos of Korean Native Cows
}

\author{
Yong-Soo, Park and Jae-Myeoung, Kim* \\ Kyongbuk Livestock Research Institute, 275. Mookri Anjung Youngju Kyongbuk, 750-871, Korea
}

\begin{abstract}
The main purpose of this study was to improve the efficiency and quality of in vitro embryo production in Korean Native Cows (KNC). We examined the effects of ovarian morphologies (Experiment 1) and the culture vessel (Experiment 2) on in vitro maturation (IVM). We measured the subsequent development rates and cell numbers of blastocysts. In Experiment 1, the ovaries of KNC were divided into six groups, based on follicle and corpus luteum (CL) morphology. The development rates to the 2- and 8-cell stages were similar among the six groups. The development rates to blastocyst stages were significantly higher in the group without a CL or follicle (WOCL/F) than in the groups with follicular cysts (FCs), regressive CLs (RCLs) or cystic CLs (CCLs) ( $<<0.05$ ). The cell number of the inner cell mass (ICM) of blastocysts in the FCs and RCLs groups, and the number of cells in the trophectoderm (TE) in the WOCL/F group, FCs, growing CLs (GCLs) and RCLs were significantly higher than in other groups ( $<<0.05)$. The total cell number (TCN) in the WOCL/F, FC and RCL groups was also significantly higher than in other groups $(\mathrm{p}<0.05)$. The ICM cell number/TCN ratio was significantly higher in the FC and RCL groups than in the GCL and DF groups $(\mathrm{p}<0.05)$. In Experiment 2, oocyte IVM was carried out in culture dishes, in 0.25 - or 0.5 -ml straws used for freezing sperm. The development rate to the 2-cell stage was significantly higher in the $0.5-\mathrm{ml}$ straw group than in the $0.25-\mathrm{ml}$ straw group. The development rates to the blastocyst stage were similar in the dish and the two straw groups. There were no differences in the cell numbers of ICM, TE or TCN or ICM cell number/TCN ratios between groups. (Key Words : Bovine, In vitro Maturation (IVM), Ovarian Morphology, Straw, Cell Uumber)
\end{abstract}

\section{INTRODUCTION}

In vitro production (IVP) of bovine embryos is carried out by collecting immature follicular oocytes from ovaries and allowing them to mature in TCM 199 medium supplemented with serum and gonadotropins (Fukui and Ono, 1989). Ninety percent of oocytes matured, and 70 to $75 \%$ of these oocytes developed to the 2-cell stage following in vitro fertilization (IVF) (Watson et al., 2000). After 5 to 7 days of in vitro culture (IVC), only 20 to $30 \%$ of IVF embryos had reached the blastocyst stage (Lonergan et al., 2003). One reason for the low blastocyst development rate is that no oocyte nuclear or cytoplasmic maturation occurs as they would in vivo. Immature oocytes are collected from 2 to 8 -mm follicles after random sampling regardless of ovarian morphology or oestrus cycle. As the follicle size increases, nuclear maturation and fertility improve (Lonergan et al., 1994). If a dominant follicle

\footnotetext{
* Corresponding Author: Jae-Myeoung, Kim. College of Medicine Pochon Cha University, 198-1, Donggu-ri Pochon Kyonggi 487-801 Korea. E-mail: dangi2359@hanmail.net Received March 27, 2006; Accepted July 9, 2006
}

grows, the rest regress (Ko et al., 1991). Oocytes collected from ovaries with a dominant follicle have slower development rates (Machatkova et al., 1996). Since we have insufficient information on the oestrus cycle of the cows when oocytes are collected for IVP, the morphological classification of the corpus luteum (CL) and follicles can enable the selection of higher quality blastocysts with faster development rates at an earlier stage. Most IVP cultures were performed in flat-bottom culture dishes, but in vivo oocytes mature in a round follicular environment. In humans, differences in IVF using a 5-ml test tube, a 4-well dish, straw used for freezing sperm and/or microdrops were studied. A straw was especially effective in human (van der Ven et al., 1989; Ranoux and Seibel, 1990; Hammitt et al., 1991) and porcine ( $\mathrm{Li}$ et al., 2003) IVF. There are no detailed reports on bovine IVM vessels. Therefore, the final goal of the present study was to improve the development and quality of bovine embryos in vitro. We examined the effects of ovarian morphology and culture vessels on IVM, as measured by embryo development stages and cell numbers of blastocysts. 


\section{MATERIALS AND METHODS}

\section{Chemicals and media}

Chemicals were purchased from Sigma Chemical Co. (St. Louis, MO, USA) unless otherwise indicated. Solutions were expressed as percent dilutions (v:v) and all media used for IVM, IVF and IVC were prewarmed at $38.5^{\circ} \mathrm{C}$ in a $5 \%$ $\mathrm{CO}_{2}$ incubator with maximum humidity for $4 \mathrm{~h}$ before use.

\section{IVM procedure}

Ovaries of Korean Native Cows were obtained at a local slaughterhouse and transported to the laboratory in saline supplemented with $25 \mu \mathrm{g} / \mathrm{ml}$ gentamicin at 25 to $28^{\circ} \mathrm{C}$ within $5 \mathrm{~h}$. Cumulus oocyte complexes (COCs) were obtained by aspiration from follicles 2 to $6-\mathrm{mm}$ in diameter using an 18-g needle attached to a $10-\mathrm{ml}$ disposable syringe. Only COCs with compact cumulus cell layers and evenly granulated ooplasm were selected. According to the method of Bavister et al. (1983) the COCs were washed 3 times in HEPES-Tyrode's albumin-lactate-pyruvate medium (TALP medium) supplemented with $25 \mathrm{mM}$ HEPES and $3 \mathrm{mg} / \mathrm{ml}$ BSA. Groups of 15 COCs were placed in TCM199 medium (Gibco, No. 12340-030; Grand Island, NY, USA) supplemented with $0.2 \mathrm{mg} / \mathrm{ml}$ pyruvate, $10 \%$ fetal bovine serum (FBS), $1 \mu \mathrm{g} / \mathrm{ml} \mathrm{FSH,} 10 \mu \mathrm{g} / \mathrm{ml} \mathrm{LH}$ and $1 \mu \mathrm{g} / \mathrm{ml}$ estradiol- $17 \beta$ under mineral oil for $20 \mathrm{~h}$ at $39^{\circ} \mathrm{C}$ in an atmosphere of $5 \% \mathrm{CO}_{2}$ and maximum humidity.

\section{IVF procedure}

Frozen semen obtained from a Korean Native bull was thawed for $1 \mathrm{~min}$ in water at $37^{\circ} \mathrm{C}$ and layered on top of a discontinuous Percoll density gradient $(2 \mathrm{ml} 45 \%$ Percoll over $2 \mathrm{ml}$ 90\% Percoll) in a 15-ml centrifuge tube (Corning; Acton, MA, USA). The sample was centrifuged for $20 \mathrm{~min}$ at $700 \times \mathrm{g}$ at room temperature $\left(22-25^{\circ} \mathrm{C}\right)$. The spermatozoa collected in the bottom fraction were washed in spermTALP medium supplemented with $3 \mathrm{mg} / \mathrm{ml}$ fraction V BSA for $10 \mathrm{~min}$ at $350 \times \mathrm{g}$. Spermatozoa were counted in a hemocytometer and diluted with sperm-TALP to give a final concentration of $25 \times 10^{6}$ spermatozoa $/ \mathrm{ml}$.

After maturation, the COCs were washed 3 times in ferTALP (TALP medium supplemented with $6 \mathrm{mg} / \mathrm{ml} \mathrm{BSA}$ and $2 \mu \mathrm{g} / \mathrm{ml}$ heparin). Groups of 15 COCs were placed in $48 \mu \mathrm{l}$ drops of fer-TALP. Two microliters of spermatozoa suspension was added to each fertilization drop, resulting in a final concentration of $1 \times 10^{6}$ spermatozoa $/ \mathrm{ml}$. Dishes were incubated for $20 \mathrm{~h}$ at $39^{\circ} \mathrm{C}$ under $5 \% \mathrm{CO}_{2}$ and maximum humidity.

\section{IVC procedure}

According to the method of Rosenkrans et al. (1993), after fertilization the presumptive zygotes were stripped of cumulus cells, washed 3 times and transferred to $20 \mu \mathrm{l}$ drops of Charles Rosenkrans 1 amino acid (CR1aa) medium with $3 \mathrm{mg} / \mathrm{ml}$ BSA. On day 3, the culture medium was exchanged for CR1aa medium supplemented with $10 \%$ FBS. All cultures were carried out under mineral oil at $39^{\circ} \mathrm{C}$ in $5 \% \mathrm{CO}_{2}$ and maximum humidity. On Day 7, the blastocysts were used for differential staining.

\section{Blastocyst differential staining}

The zona of blastocysts was removed by treatment with $0.5 \%$ pronase and washed 5 times in HEPES-TALP medium. Zona-free blastocysts were incubated in a 1:5 dilution of rabbit anti-bovine whole serum in HEPES-TALP medium for $1 \mathrm{~h}$. After washing 5 times in HEPES-TALP medium again, blastocysts were reincubated in a 1:10 dilution of a guinea pig complement in HEPES-TALP medium supplemented with $4 \mu \mathrm{g} / \mathrm{ml}$ propidium iodide (PI) and 4 $\mu \mathrm{g} / \mathrm{ml}$ bisbenzimide for $1 \mathrm{~h}$. Presumptive stained blastocysts were mounted on a slide and the cells were counted under a fluorescence microscope (Olympus, Tokyo, Japan). The bisbenzimide stained inner cell mass (ICM) nuclei fluoresced blue, and trophectoderm (TE) nuclei, which stained with both bisbenzimide and PI, fluoresced red or pink.

\section{Experimental designs}

Experiment 1: Ovarian morphology assessment

In the control group, oocytes were collected from ovaries without CLs or follicles (WOCL/F group). The treatment groups were oocytes collected from ovaries with a dominant follicle (DF; follicle under $2 \mathrm{~cm}$ in diameter), follicular cystic (FC; follicle over $2 \mathrm{~cm}$ ), regressive CL (RCL; CL under $0.5 \mathrm{~cm}$ ), growing CL (GCL; CL 0.5 to 2 $\mathrm{cm}$ ), and cystic CL (CCL; CL over $2 \mathrm{~cm}$ ).

\section{Experiment 2 : IVM vessels}

Oocytes used in Experiment 2 were collected from ovaries with WOCL/F. The IVM vessels used were a culture dish (control group; Nunc, Roskilde, Denmark), a 0.25-ml straw, or a 0.5-ml straw (experimental groups; Fujihira, Tokyo, Japan). For the control group, 50- $\mu$ l microdrops with 15 immature oocytes were added and left to mature. For the experimental groups, 15 immature oocytes in IVM medium were added to a 0.25 - or $0.5-\mathrm{ml}$ straw and left to mature.

\section{Statistical analyses}

Embryo development data were analyzed by the $x^{2}$-test. The cell numbers were arcsine transformed and analyzed by the General Linear Models Procedure with the Statistical Analysis System (Cary, CA, USA). Treatment means were compared using the Duncan's multiple range test. $\mathrm{P}$ values less than 0.05 were considered significantly different. 
Table 1. Effects of ovarian morphology on the subsequent embryonic development of Korean Native Cow oocytes

\begin{tabular}{|c|c|c|c|c|}
\hline \multirow{2}{*}{ Morphology } & \multirow{2}{*}{$\mathrm{n}$} & \multicolumn{3}{|c|}{ No. (\%) of oocytes developed to } \\
\hline & & $\geq 2$-cell & 8-cell & Blastocyst \\
\hline Without corpus luteum or follicle & 265 & $223(84.1)$ & $137(51.6)^{\mathrm{a}}$ & $57(21.5)^{\mathrm{a}}$ \\
\hline Follicular cyst & 135 & 95 (70.3) & $50(37.0)^{\mathrm{b}}$ & $17(12.5)^{b}$ \\
\hline Growing corpus luteum & 344 & $261(75.8)$ & $158(45.9)^{\mathrm{ab}}$ & $68(19.7)^{\mathrm{ab}}$ \\
\hline Regressive corpus luteum & 501 & $391(78.0)$ & $230(45.9)^{\mathrm{ab}}$ & $76(15.1)^{b}$ \\
\hline Cystic corpus luteum & 208 & $156(75.0)$ & $92(44.2)^{\mathrm{ab}}$ & $28(13.4)^{b}$ \\
\hline Dominant follicle & 560 & 409 (73.0) & $243(43.3)^{b}$ & $110(19.6)^{\mathrm{ab}}$ \\
\hline
\end{tabular}

${ }_{\mathrm{a}, \mathrm{b}}$ Values in a column that differ significantly $(\mathrm{p}<0.05)$ are denoted by differing superscripts.

Table 2. Effects of ovarian morphology on the number of cells in the inner cell mass and trophectoderm, and total cell number in Korean Native Cow blastocysts

\begin{tabular}{|c|c|c|c|c|c|}
\hline \multirow{2}{*}{ Morphology } & \multirow{2}{*}{$\mathrm{n}$} & \multicolumn{3}{|c|}{ Average no. of cells } & \multirow{2}{*}{$\begin{array}{c}\text { Inner cell mass/Total } \\
(\%)\end{array}$} \\
\hline & & Inner cell mass & Trophectoderm & Total & \\
\hline Without corpus luteum or follicle & 16 & $33.5 \pm 14.0^{\mathrm{ab}}$ & $102.5 \pm 19.2^{\mathrm{a}}$ & $136.0 \pm 29.2^{\mathrm{a}}$ & $24.0 \pm 6.7^{\mathrm{ab}}$ \\
\hline Follicular cyst & 16 & $40.3 \pm 13.1^{\mathrm{a}}$ & $100.0 \pm 33.3^{\mathrm{a}}$ & $140.4 \pm 29.4^{\mathrm{a}}$ & $30.5 \pm 13.3^{\mathrm{a}}$ \\
\hline Growing corpus luteum & 16 & $18.9 \pm 12.1^{\mathrm{c}}$ & $109.9 \pm 33.0^{\mathrm{a}}$ & $128.8 \pm 33.5^{\mathrm{ab}}$ & $14.8 \pm 7.6^{\mathrm{c}}$ \\
\hline Regressive corpus luteum & 16 & $41.8 \pm 18.2^{\mathrm{a}}$ & $97.8 \pm 17.5^{\mathrm{a}}$ & $136.7 \pm 29.4^{\mathrm{a}}$ & $30.0 \pm 9.2^{\mathrm{a}}$ \\
\hline Cystic corpus luteum & 16 & $30.6 \pm 26.2^{\mathrm{ab}}$ & $74.1 \pm 28.4^{\mathrm{b}}$ & $105.3 \pm 29.5^{\mathrm{b}}$ & $27.8 \pm 19.7^{\mathrm{ab}}$ \\
\hline Dominant follicle & 16 & $24.6 \pm 10.7^{\mathrm{bc}}$ & $91.6 \pm 41.1^{\mathrm{ab}}$ & $116.3 \pm 45.7^{\mathrm{ab}}$ & $19.9 \pm 8.4^{\mathrm{bc}}$ \\
\hline
\end{tabular}

$\overline{\mathrm{a}, \mathrm{b}, \mathrm{c}}$ Values in a column that differ significantly $(\mathrm{p}<0.05)$ are denoted by differing superscripts. Values are presented as the mean \pm SD.

Table 3. Effect of the culture vessel on in vitro maturation in Korean Native Cow oocytes

\begin{tabular}{lcccc}
\hline \multirow{2}{*}{ Vessels } & \multirow{2}{*}{$\mathrm{n}$} & \multicolumn{3}{c}{ No. (\%) of oocytes developed to } \\
\cline { 3 - 5 } & & $\geq 2$-cell & 8-cell & Blastocyst \\
\hline Culture dish & 210 & $152(72.3)^{\mathrm{ab}}$ & $111(52.8)^{\mathrm{a}}$ & $56(26.6)$ \\
$0.25-\mathrm{ml}$ straw & 195 & $127(65.1)^{\mathrm{b}}$ & $84(43.1)^{\mathrm{b}}$ & $45(23.1)$ \\
$0.5-\mathrm{ml}$ straw & 195 & $145(74.3)^{\mathrm{a}}$ & $99(50.7)^{\mathrm{ab}}$ & $60(30.7)$ \\
\hline
\end{tabular}

a, b Values in a column that differ significantly $(\mathrm{p}<0.05)$ are denoted by differing superscripts.

\section{RESULTS}

\section{Experiment 1: Ovarian morphology}

The cleavage rate ( $\geq 2$-cell) was similar among treatments (Table 1). The development rate to the 8-cell stage in the control WOCL/F group was significantly higher than in the FC and DF groups $(\mathrm{p}<0.05)$. The development rate to the blastocyst stage was significantly higher in the control group than in the FC, RCL, and CCL groups $(\mathrm{p}<0.05)$. ICM cell numbers of blastocysts in the FC and RCL groups were significantly higher than in the GCL and DF groups ( $p<0.05$, Table 2 ). TE cell numbers in the control, FC, GCL, and RCL groups were significantly higher than the PCL group $(\mathrm{p}<0.05)$. The ICM cell number/TCN ratio was significantly higher in the FC and RCL groups than in the GCL and DF groups $(\mathrm{p}<0.05)$.

\section{Experiment 2: IVM vessels}

The cleavage rate in the $0.5-\mathrm{ml}$ straw group was significantly higher than that in the 0.25 -ml straw group $(\mathrm{p}<0.05$, Table 3$)$. The development rate to the 8 -cell stage was significantly higher in the control culture dish group than in the $0.25-\mathrm{ml}$ straw group $(\mathrm{p}<0.05)$. The development rates to the blastocyst stage were similar among the 3 treatments. There were no differences in ICM, TE, TCN and ICM/TCN cell numbers between treatments (Table 4).

\section{DISCUSSION}

There was no difference in the maturation rate of immature oocytes collected during different phases of the oestrus cycle (Leibfried and First, 1979), but the blastocyst development rate of oocytes collected during the luteal phase was higher than that of those collected during the follicular phase (Machatkova et al., 1996). Development rates of oocytes collected from ovaries with a CL or without a DF tended to be higher (Varisanga et al., 1998). In the present study, however, the development rate of control oocytes collected from ovaries during the inactive stage was the highest (Table 1). In the ovaries with CL, GCL had higher developmental competence than RCL and CCL (Table 1).

The blood progesterone levels were $0.3 \mu \mathrm{g} / \mathrm{ml}$ in WOCL/F, $0.5 \mu \mathrm{g} / \mathrm{ml}$ in RCL, $1.6 \mu \mathrm{g} / \mathrm{ml}$ in GCL, and, notably, over $7.0 \mu \mathrm{g} / \mathrm{ml}$ in the CCL group. These levels were increased with larger CL sizes (Kamishita et al., 1999; Son et al., 1999). In addition, the blood progesterone level was $4.7 \mu \mathrm{g} / \mathrm{ml}$ when ovaries were FC (Kang et al., 2006). Kamishita et al. (1999) reported that the development rate of embryos decreased with an increase in progesterone level. In the present study, the development rate of embryos from ovaries with CCL and FC was decreased as progesterone level increased. Oocytes from ovaries with CCL not only showed decreased embryo development, but also a lower 
Table 4. Effect of IVM culture vessel on the number of cells in the inner cell mass and trophectoderm, and total cell number in Korean Native Cow blastocysts

\begin{tabular}{|c|c|c|c|c|c|}
\hline \multirow{2}{*}{ Vessels } & \multirow{2}{*}{$\mathrm{n}$} & \multicolumn{3}{|c|}{ Average no. of cells } & \multirow{2}{*}{ Inner cell mass/Total (\%) } \\
\hline & & Inner cell mass & Trophectoderm & Total & \\
\hline Culture dish & 12 & $26.3 \pm 4.3$ & $75.0 \pm 18.4$ & $101.3 \pm 16.2$ & $26.8 \pm 7.4$ \\
\hline $0.25-m l$ straw & 12 & $36.1 \pm 25.0$ & $72.8 \pm 14.5$ & $109.0 \pm 32.3$ & $30.7 \pm 11.2$ \\
\hline 0.5-ml straw & 12 & $35.3 \pm 11.4$ & $86.5 \pm 21.7$ & $121.7 \pm 21.5$ & $29.0 \pm 10.7$ \\
\hline
\end{tabular}

Values are presented as the mean \pm SD.

number of total cells (Table 2).

IVF in a 5-ml test tube, in a 4-well dish, in a straw, and in a microdrop were compared. The straw was found to be most effective for freezing human sperm (van der Ven et al., 1989; Ranoux and Seibel, 1990; Hammitt et al., 1991) and porcine embryos ( $\mathrm{Li}$ et al., 2003). Boone and Shapiro (1990) reported that, in mouse IVC, a petri dish produced more toxins than 4-well plates. Historically, the most popular and effective method for IVF, IVM, and IVC was the use of microdrops on a petri dish, but fertilized embryos are coated with mineral oil in the microdrop method, resulting in oil contamination and time wasted equilibrating embryos before culture (Gardner and Leese, 2000). In the present study, we showed that dish and straw IVM vessels (as shown in Tables 3 and 4) had similar blastocyst development rates and cell numbers, but development rate at the 2- and 8-cell stages tended to be higher for $0.5-\mathrm{ml}$ straws than $0.25-\mathrm{ml}$ straws. This difference is attributed to the need for adequate space for material movement and metabolism (Rieger and Loskutoff, 1994; Roberts et al., 2002). In bovine IVM, no effects of culture vessel type have been proposed. Further studies will analyze the effect of sperm freezing straws on IVF and IVC in producing bovine embryos.

The ultimate test of embryo quality is the ability to cause pregnancy and produce a live offspring. Due to the impracticality of transferring every embryo, we used blastocyst morphology (Linder and Wright, 1983), hatching rate (Hernandez-Ledezma et al., 1996), blastocyst cell number (Papaioannou and Ebert, 1988), and cryotolerance (Enright et al., 2000) as measures of embryo quality. Blastocysts produced in vivo have a larger number and proportion of ICM cells than those produced in vitro (Iwasaki et al., 1990). There are many factors, such as serum (Watson et al., 2000), amino acid (Park et al., 2004), IVM duration (Park et al., 2005) and culture conditions (van Soom et al., 1996) which affect number of cells in blastocysts. However, this number was not affected by follicle size (Lequarre et al., 2005). In the present study, the GCL group had a low number of ICM cells and an even lower ICM cell number/TCN ratio, but the CCL group had a low number of trophectoderm and total cells (Table 2). The quality of blastocysts produced by the FC and RCL groups tended to have higher cell numbers and ICM cell number/TCN ratios (Table 2). Thus, the ovaries with GCL and CCL were not effective in the production of highquality blastocysts in vitro.

In conclusion, the data regarding the effects of ovarian morphology and culture vessel on IVM, using measures of embryo development rates and blastocyst cell numbers in Korean Native Cows, suggested that morphological grades $\mathrm{CL}$ and $\mathrm{F}$ of ovaries may offer greater efficiency of embryonic development and quality.

\section{REFERENCES}

Bavister, B. D., M. L. Leibfried and G. Lieberman. 1983. Development of preimplantation embryos of golden hamster in a defined culture medium. Biol. Reprod. 28:235-247.

Boone, W. R. and S. S. Shapiro. 1990. Quality control in the in vitro fertilization laboratory. Theriogenol. 33:23-50.

Enright, B. P., P. Lonergan, A. Dinnyes, T. Fair, F. A. Ward, X. Yang and M. P. Boland. 2000. Culture of in vitro produced bovine zygotes in vitro vs. in vivo: Implications for early embryo development and quality. Theriogenol. 54:659-673.

Fukui, Y. and H. Ono. 1989. Effects sera, hormonse and granulosa cells added to culture medium for in vitro maturation, fertilization, cleavage and development of bovine oocytes. J. Reprod. Fertil. 86:501-506.

Gardner, D. K. and H. J. Leese. 2000. Assessment of embryo metabolism and viability. In; Handbook of in vitro fertilization (Ed. A. O. Trounson, D. K. Gardner). CRC press, New York, pp. 347-372.

Hammitt, D. G., D. L. Walker, C. H. Syrop, T. M. Miler and M. R. Bennett. 1991. Treatment of sever mala-factor infertility with high concentrations of motile sperm by microinsemination in embryo cryopreservation straws. J. In vitro Fertil. Embryo Transfer 8:101-110.

Hernandez-Ledezma, J. J., C. Villanueva, J. D. Sikes and H. M. Kubisch. 1996. Increasing the rate of blastocyst formation and hatching from in vitro-produced bovine zygotes. Theriogenol. 46:961-969.

Iwasaki, S., N. Yoshiba, H. Ushijima, S. Watanabe and T. Nakahara. 1990. Morphology and proportion of inner cell mass of bovine blastocysts fertilized in vitro and in vivo. J. Reprod. Fertil. 90:279-284.

Kamishita, H., M. Takagi, Y. H. Choi, M. P. B. Wijayagunawardane, K. Miyazawa and K. Sato. 1999. Development of in vitro matured and fertilized bovine embryos cocultured with bovine oviductal epithelial cells obtained from oviducts ipsilateral to cystic follicles. Anim. Reprod. Sci. 56:201-209.

Kang, H. J., C. S. Lee, I. H. Kim, I. P. Mo, K. C. Lee and G. H. Suh. 2006. Evaluation of functional status of ovarian cysts in 
slaughtered Korean native cows. Kor. J. Emb. Trans. 21:59-67. Ko, J., J. Kastelic, M. Del Campo and O. Ginther. 1991. Effect of a dominant follicle on ovarian follicular dynamics during oestrus cycle in heifers. J. Reprod. Fertil. 91:511-519.

Leibfried, L. and N. L. First. 1979. Characterization of bovine follicular oocytes and their ability to mature in vitro. J. Anim. Sci. 48:76-86.

Lequarre, A. S., C. Vigneron, F. Ribaucour, P. Holm, I. Donnay, R. Dalbies-Tran, H. Callesen and P. Mermillod. 2005. Influence of antral follicle size on oocyte characteristics and embryo development in the bovine. Theriogenol. 63:841-859.

Li, Y. H., W. Ma, M. Li, L. Hou, L. H. Jiao and W. H. Wang. 2003. Reduced polyspermic penetration in porcine oocytes inseminated in a new in vitro fertilization (IVF) system: Straw IVF. Biol. Reprod. 69:1580-1585.

Linder, G. M. and W. W. Wright. 1983. Bovine embryo morphology and evaluation. Theriogenol. 20:407-416.

Lonergan, P., P. Monaghan, D. Rizos, M. P. Boland and I. Gordon. 1994. Effect of follicle size on bovine oocyte quality and developmental competence following maturation, fertilization, and culture in vitro. Mol. Reprod. Dev. 37:48-53.

Lonergan, P., D. Rizos, A. Gutierrez-Adan, T. Fair and M. P. Boland. 2003. Oocyte and embryo quality: Effect of origin, culture conditions and gene expression patterns. Reprod. Dom. Anim. 38:259-267.

Machatkova, M., E. Jokesova and V. Dvoracek. 1996. Developmental competence of bovine embryos derived from oocytes collected at various stages of the estrus cycle. Theriogenol. 45:801-810.

Papaioannou, V. E. and K. M. Ebert. 1988. The preimplantation pig embryo: Cell number and allocation to trophectoderm and inner cell mass of the blastocyst in vivo and in vitro. Development 102:793-803.

Park, Y. S., S. S. Kim, S. H. Choi, N. C. Park, M. D. Byun and H. D. Park. 2004. Effects of amino acid in in-vitro maturation medium on nuclear maturation and embryo development of Korean native cow. Reprod. Dev. Biol. 28:29-36.
Park, Y. S., S. S. Kim, J. M. Kim, H. D. Park and M. D. Byun. 2005. The effects of duration of in vitro maturation of bovine oocytes on subsequent development, quality and transfer of embryos. Theriogenol. 64:123-134.

Ranoux, C. and M. M. Seibel. 1990. New techniques in fertilization: intravaginal culture and microvolume straw. J. In vitro Fertil. Embryo. Transfer. 7:6-8.

Rieger, D. and N. M. Loskutoff. 1994. Changes in the metabolism of glucose, pyruvate, glutamine and glycine during maturation of cattle oocytes in vitro. J. Reprod. Fertil. 100:257-262.

Roberts, R., S. Franks and K. Hardy. 2002. Culture environment modulates maturation and metabolism of human oocytes. Hum. Reprod. 17:2950-2956.

Rosenkrans, C. F. Jr, G. Q. Zeng, G. T. McNamara, P. K. Schoff. and N. L. First. 1993. Development of bovine embryos in vitro as affected by energy substrates. Biol. Reprod. 49:459-462.

Son, C. H., B. K. Kang, H. S. Choi, W. H. Lim, H. G. Kang, K. S. Oh, J. B. Shin and G. H. Suh. 1999. Development of differential diagnosis and treatment method of reproductive disorders using ultrasonography in cows III. Differential diagnosis between developing and regressing corpus luteum. Kor. J. Vet. Clin. Med. 16:118-127.

van der Ven, H. H., K. Hoebbel, S. Al-Hasani, K. Diedrich and D. Kerbs. 1989. Fertilization of oocytes in capillary tubes with very small numbers of spermatozoa. Hum. Reprod. 4:72-76.

van Soom, A., M. Boerjan, M. T. Ysebaert and A. de Kruif. 1996. Cell allocation to the inner cell mass and the trophectoderm in bovine embryos cultured in two different media. Mol. Reprod. Dev. 45:171-182.

Varisanga, M. D., C. Sumantri, M. Murakami, M. Fahrudin and T. Suzuki. 1998. Morphological classification of the ovaries in relation to the subsequent oocyte quality for IVF-produced bovine embryos. Theriogenol. 50:1015-1023.

Watson, A. J., P. Sousa, A. Caveney, L. C. Barcroft, D. Natale, J. Urquhart and M. E. Westhusin. 2000. Impact of bovine oocyte maturation media on oocyte transcript levels, blastocyst development, cell number, and apoptosis. Biol. Reprod. 62:355-364. 